\title{
Communication \\ An Unconventional Ligand for Scribble PDZ-4 Domain Mediates Its Interaction with Dusp26
}

\author{
Raffaella Gallo (D, Erika De Sensi, Francesca Storino and Simona Panni *D
}

Dipartimento di Biologia Ecologia Scienze della Terra (DiBEST), Università della Calabria, Via Pietro Bucci Cubo 6/C, 87036 Rende, Italy; raffaella.gallo@uzh.ch (R.G.); erikadesensi.bio@gmail.com (E.D.S.); francesca.storino@virgilio.it (F.S.)

* Correspondence: simona.panni@unical.it

\begin{abstract}
PDZ domains are involved in many cellular processes and are key regulators of the cell physiology. A huge number of studies have investigated the binding specificity of PDZ domains to the carboxyl-terminal sequence of target proteins, while the molecular mechanisms that mediate the recognition of internal binding regions are largely unexplored. In the present study, we describe a ligand motif located in the catalytic domain of the phosphatase Dusp26 which mediates its binding to the PDZ-4 of Scribble. Site-directed mutagenesis identified a conserved tyrosine residue as relevant for the binding. The interaction with the PDZ domain could help the phosphatase to recruit its specific targets.
\end{abstract}

Keywords: PDZ domain; PDZ internal binding motif; Dusp26; scribble; dual-specificity phosphatase; phosphatase

check for updates

Citation: Gallo, R.; De Sensi, E. Storino, F.; Panni, S. An Unconventional Ligand for Scribble PDZ-4 Domain Mediates Its Interaction with Dusp26. BioChem 2022, 2, 83-92. https://doi.org/ 10.3390/biochem2010006

Academic Editor: Yehia Mechref

Received: 30 November 2021

Accepted: 9 February 2022

Published: 15 February 2022

Publisher's Note: MDPI stays neutral with regard to jurisdictional claims in published maps and institutional affiliations.

Copyright: (c) 2022 by the authors. Licensee MDPI, Basel, Switzerland. This article is an open access article distributed under the terms and conditions of the Creative Commons Attribution (CC BY) license (https:// creativecommons.org/licenses/by/ $4.0 /)$.

\section{Introduction}

Interactions between proteins are often mediated by small globular protein domains which recognize short linear motifs on the surface of their target partners [1,2]. PDZ domains are interaction modules of approximately 100 amino acids, widespread in almost all eukaryotic proteomes, whose function is to organize signaling complexes and localize enzymes with their substrates at suitable cell compartments [3,4]. The term PDZ indicates the three proteins where it was first identified: the synaptic protein PSD95, the Drosophila junction protein Disc-Large, and the tight junction protein ZO1 The crystal structures of PDZ domains show that they are composed of a beta-sandwich comprising 5-6 beta strands and two alpha helices $[5,6]$. Their binding specificity is commonly mediated through the recognition of a short peptide, often indicated as the PBM (PDZ-binding motif), situated at the carboxyl-terminus of the proteins $[7,8]$. Several studies have attempted to decipher the rules that govern these interactions, and three main classes of ligands have been described: X S/T X $\Phi \mathrm{COOH} ; X \Phi \times \Phi \mathrm{COOH} ; \times \mathrm{E} / \mathrm{D} \times \Phi \mathrm{COOH}$ (with $\Phi$ being any hydrophobic amino acid and $X$ being any residue) [9-11]. However, subsequent studies showed that the mechanism of recognition was more complex than initially believed, and that PDZ domains also recognize internal peptide motifs and phospholipids [12-14]. Several of these atypical interactions are well characterized; for example, the structures of syntrophin PDZ with nNOS [12], the Dishevelled (Dvl) PDZ with synthetic ligands [15], and Par6 with Pals1 [16] have been solved, showing that internal ligands can be accommodated in the same binding pocket of the PDZ domain used by the carboxyterminal peptides.

We have previously demonstrated that the PDZ protein Scribble binds to the phosphatase Dusp26 both in vitro and in vivo [17], and we hypothesized a possible role of Scribble as a scaffold to target the phosphatase toward its substrates. The interaction with Dusp26 was mediated by the fourth PDZ of Scribble [17]. Several studies have shown that this domain has a different behavior from the other three, despite the sequence similarity in the binding groove. Library screenings with carboxyl-terminal peptides have failed 
to find a consensus sequence for the PDZ-4 of Scribble [11] or have found peptides with a weak binding affinity $[18,19]$. Few proteins have been reported as interactors of the PDZ-4 of Scribble. Among them, Dlc3, ADRA1D, APC, and HPVE6 interact with Scribble through their carboxy-terminus, but the interaction is not limited to the PDZ-4 $[15,20,21]$, while NOS1AP and TBEV NS5 exclusively interact with the PDZ-4, through an internal binding motif [22-24]. In the present paper, we show that the protein phosphatase Dusp26 contains an internal motif that it is able to bind to the PDZ-4 of Scribble (Scrib-4). This motif surrounds a well-conserved region, and it includes a tyrosine which is crucial for the binding.

\section{Materials and Methods}

\subsection{Constructs and Plasmids}

Human Scribble cDNA was kindly provided by Prof. L. Banks, and single PDZ domains were subcloned into the pGex vector as GST recombinant proteins and into pET28 as histidine recombinant protein. OpenBiosystem purchased the Dusp26 cDNA, which was cloned in pET28, pQE30, and pGex plasmids. Dusp26 deletion mutants were subcloned in the same plasmids using the following primers:

For the CD construct lacking residues 1-59

F: $5^{\prime}$ TAGCTGGATCCAACCATGCCGACGAGGTC $3^{\prime}$

R: $5^{\prime}$ AGCGAGAAGCTTTCATGCTTCCAGACCCTG $3^{\prime}$

For the CD-D3 construct lacking 1-59 and the 3 last amino-acids

F: $5^{\prime}$ TAGCTGGATCCAACCATGCCGACGAGGTC $3^{\prime}$

R: $5^{\prime}$ ACGTAGAATTCTCAACCCTGCCGCAGCCTGCG $3^{\prime}$

For the 147-190 construct

F: $5^{\prime}$ TAGCTGGATCCGGGAAGATCCTGGTGCAT $3^{\prime}$

$R: 5^{\prime}$ ACGTAGAATTCTCAGGGGATGATGCCTCG $3^{\prime}$

\subsection{Site-Specific Mutagenesis}

Mutant Dusp26 coding sequences (Y166A and Y170A) were assembled from two overlapping DNA fragments obtained by PCR amplification with pairs of complementary primers, each carrying the mutated sequence, and two primers that prime from the $5^{\prime}$ and $3^{\prime}$-ends of the wildtype Dusp26 catalytic domain sequence. This latter pair of primers contains BamHI and HindIII restriction sites, respectively, for directional cloning into the pQE30. Their sequences are as follows:

F: $5^{\prime}$ TAGCTGGATCCAACCATGCCGACGAGGTC $3^{\prime}$

R: $5^{\prime}$ AGCGAGAAGCTTTCATGCTTCCAGACCCTG $3^{\prime}$

The mutagenic primers used in the first PCR amplification step were as follows:

For Y166A

F: $5^{\prime}$ CCCTGGTACTGGCCGCCCTCATGCTGTACCACC $3^{\prime}$

R: $5^{\prime}$ GGTGGTACAGCATGAGGGCGGCCAGTACCAGGG $3^{\prime}$

For Y170A

F: $5^{\prime}$ CCTACCTCATGCTGGCCCACCACCTTACCCTCG $3^{\prime}$

R: $5^{\prime}$ CGAGGGTAAGTGGTGGGCCAGCATGAGGTAGG $3^{\prime}$

For Y166A, Y170A

F: $5^{\prime}$ CCGCCCTCATG CTGGCCCACCACCTTACCCTCG $3^{\prime}$

R: $5^{\prime}$ CGAGGGTAAGGTGGTGGGCAGCATGAGGGCGG $3^{\prime}$

Carboxy-terminus mutants L209A and E210A were obtained, respectively, with the following reverse primers:

$5^{\prime}$ ACGTAGAATTCTCATGCTTCCGCACCCTGCCG $3^{\prime}$

$5^{\prime}$ ACGTAGAATTCTCATGCTGCCAGACCCTGCCG $3^{\prime}$

\subsection{Recombinant Protein Production and Purification}

PDZ domains cloned in pGex vectors were expressed in E. coli BL21 Rosetta as glutathione S-transferase (GST) fusion products. The proteins were purified by standard 
procedures with Glutathione Sepharose 4B and, when necessary, eluted from the column with $10 \mathrm{mM}$ glutathione. Their purity was assessed by polyacrylamide gel electrophoresis. Proteins were dialyzed against PBS buffer to remove glutathione, and their concentration was estimated using the Bradford assay (Bio-Rad Hercules, CA, USA).

\subsection{Pull-Down Assay}

E. coli BL21 Rosetta expressing recombinant wildtype (wt) or mutated Dusp26, with a histidine tag, was lysed by sonication. After centrifugation, the extracts were quantified and incubated for $2 \mathrm{~h}$ at $4{ }^{\circ} \mathrm{C}$ with 25-50 $\mu \mathrm{g}$ of the GST-fused PDZ bound to Glutathione Sepharose beads. The resins were washed four times with $500 \mathrm{~mL}$ of PBS buffer $0.05 \%$ Tween, and the bound proteins were recovered by heating to $92{ }^{\circ} \mathrm{C}$ in Laemmli buffer for 5 min (50 mM Tris pH 6.8, 100 mM DTT, 2\% SDS, 1\% Bromophenol Blue, 10\% glycerol), analyzed by electrophoresis on SDS polyacrylamide gel (concentration from $12 \%$ to $20 \%$ according to the molecular weight of the proteins), and blotted onto nitrocellulose membranes. A Page Ruler Plus (ThermoFisher, Waltham, MA, USA) molecular weight marker was used to evaluate the molecular weight of the proteins. The membranes were blocked for $2 \mathrm{~h}$ at room temperature (RT) or overnight at $4{ }^{\circ} \mathrm{C}$ in PBS containing $3 \%$ skimmed-milk powder (blocking solution), and then incubated for $2 \mathrm{~h} 4{ }^{\circ} \mathrm{C}$ with mouse anti-His (GE Healthcare) 1:2000 in blocking solution. After four washes in PBS 0.05\% Tween, membranes were incubated with anti-mouse peroxidase-conjugated (Sigma-Aldrich, Milan, Italy) for $45 \mathrm{~min}$ at RT in blocking solution, and washed again four times in PBS 0.05\% Tween. Bound Dusp26 was revealed by chemiluminescence.

\subsection{Affinity Chromatography}

The peptide SRSATLVLAYLMLYHH was synthesized by BioFab-Research and dissolved in $50 \%$ methanol-PBS to a final concentration of $0.5 \mathrm{mM}$. Then, $2 \mu \mathrm{L}$ was added to $50 \mu \mathrm{L}$ of streptavidin beads (Sigma-Aldrich) for $1 \mathrm{~h}$ at $4{ }^{\circ} \mathrm{C}$ to create the affinity resin. After three washes, the beads were used for the chromatography. Cell extracts containing Scrib-4 were incubated with the affinity resin for $2 \mathrm{~h}$ at $4{ }^{\circ} \mathrm{C}$, and then washed. The bound domain was revealed by Western blotting.

\subsection{ELISA Assay}

ELISA assays were performed in microtiter plates, coated with $2 \mu \mathrm{g} / \mathrm{mL}$ Dusp26-GST or GST in PBS overnight $(\mathrm{O} / \mathrm{N})$ at $4{ }^{\circ} \mathrm{C}$. After blocking in PBS-4\% BSA, the wells were incubated with His-Scribble PDZ-4 fusion protein in PBS-4\% BSA for $2 \mathrm{~h}$ at $4{ }^{\circ} \mathrm{C}$. After 10 washes, anti-His antibody was added to PBS-4\% BSA for $1 \mathrm{~h}$ at room temperature, followed by anti-mouse peroxidase-conjugated (Sigma) for $45 \mathrm{~min}$ at $4{ }^{\circ} \mathrm{C}$. After 10 washes, the reaction was revealed with ABTS and read at $405 \mathrm{~nm}$.

\subsection{Molecular Docking Analysis}

The crystal structures of human Scribble PDZ-4 and human Dusp26 were downloaded from RCSB protein data bank (PDB 1UJU and 4HRF, respectively). Molecular docking was carried out with HADDOCK (high-ambiguity-driven protein-protein docking) [25]. Prior to molecular docking, the active residues (i.e., directly involved in the interaction) were determined using CPORT [26] and the available structural information. We considered active the Scrib- 4 residues that constitute the binding site (17-24, 25-28, 81-90, numbers referring to PDB 1UJU) and the DUSP26 residues 156-172. Solutions were scored according to a linear combination of energetics terms, resulting in the HADDOCK score. This score takes into consideration the van der Waals energy, electrostatic energy, desolvation energy, energy from restraint violations, and the buried surface area as described in detail at https: / / www.bonvinlab.org/software/haddock2.2/scoring/ (accessed on 20 November 2021). For the selected solution, the HADDOCK score was $-84.1 \pm 1.2)$, and the complex prediction had a high quality according to the CAPRI criteria (Critical Assessment of Predicted Interactions) ( $f_{\text {nat }}: 0.685$; i-RMSD: 0.267; l-RMSD: 1.130) [27]. The value of the binding free 
energy $(\Delta \mathrm{G})$ was predicted with PRODIGY (Protein Binding Energy Prediction) [28]: $\Delta \mathrm{G}$ : $-9.1 \mathrm{kcal} \cdot \mathrm{mol}^{-1}$. UCSF Chimera was used for visualization and analysis of the molecular structures [29].

\section{Results}

\subsection{Scribble PDZ-4 Binds to an Internal Site of Dusp26}

We previously demonstrated that Dusp26 binds to the PDZ-4 of Scribble [17]. PDZ domains very often bind to the C-terminal tail of the target proteins.

To investigate the relevance of the Dusp26 carboxy-terminus in the binding, we mutated the amino acids L209A and E210A (Figure 1A) and expressed the constructs in E. coli BL21 as $6 \times$ His-tagged recombinant proteins. L209 corresponds to the P-2 position, considered a key residue for the binding, while a negatively charged amino acid in position P-1 (E210) has been suggested to be crucial for the binding of the $\alpha 1 \mathrm{D}$-adrenergic receptor to the Scrib-4 domain [21].
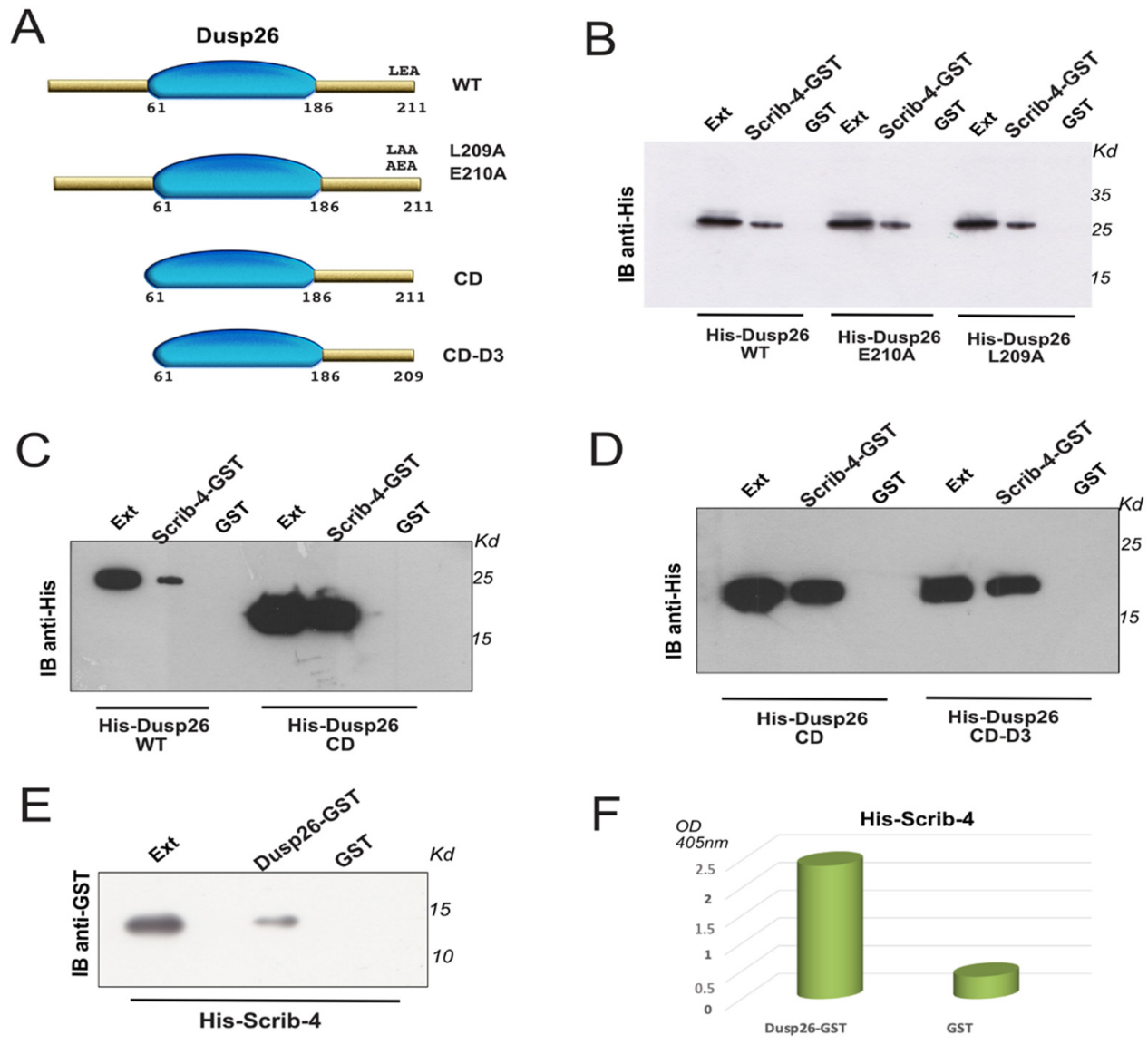

Figure 1. Dusp26 amino-terminus and carboxy-terminus are not indispensable to bind to Scribble PDZ-4. (A) Schematic representation of Dusp26 constructs. The phosphatase Dusp26 is a small protein of 211 amino acids constituting an N-terminal region of 60 amino acids, a catalytic domain (aa 61-186), and a short carboxyterminal region (187-211). (B) His-Dusp26 E210A and L209A mutants maintain the capability to recognize Scrib-4 in pull-down assays. Scrib-4 fused to GST was used as a bait and anti-His immunoblot revealed the bound phosphatase. Ext lane shows the input extracts, and GST alone was used as a control. (C) In a pull-down assay, performed as in (B), the CD mutant (aa 60-210) binds to Scrib-4-GST. (D) The CD mutant, lacking the 3 carboxyl-terminal amino-acids, still binds to Scrib-4-GST. (E) Pull-down assay with Dusp26 fused to GST used as a bait and Scrib-4 fused to His-tag. Anti-GST immunoblot revealed the bound domain. (F) ELISA test with Dusp26-GST-coated plates incubated with His-Scrib-4. The bound protein was detected by the anti-His antibody. 
We observed that both mutations did not affect the binding of Dusp26 to Scrib-4 (Figure 1B).

It was shown in the literature that, while the full-length Dusp26 protein is mainly insoluble, a deletion of the amino-terminal 60 amino acids of the protein results in a more stable and more soluble construct [30]. For subsequent analyses, we purified a deleted construct missing the first 60 amino acids but containing the catalytic domain (CD), and we used this construct to create the CD-D3 protein, lacking the carboxyl-terminal motif LEA (Figure 1A). The histidine-tagged CD protein was more soluble than the full-length protein and maintained the ability to bind to Scrib-4 (Figure 1C). Moreover, the carboxylterminal LEA motif was not essential to the binding, since the CD-D3 construct still binds (Figure 1D). We also expressed the CD construct as GST fusion, and we evaluated its ability to bind to His- Scrib-4 with both pull-down and ELISA assays. As shown in Figure 1E,F, the catalytic domain was able to bind to Scribble PDZ-4 irrespective of the tag used. We conclude that an internal region of the Dusp26 is involved in the binding with Scrib-4.

\subsection{Mapping the Internal Region Binding Site}

Since the deletion of the first 60 amino acids or of the carboxy-terminus did not affect its binding to Scribble, we investigated whether the binding region was enclosed in the catalytic domain of Dusp26. Interestingly, the region containing amino acids 147-190, which includes the AYLM motif conserved among several Dusp phosphatases, has sequence similarity with a Scrib-4 ligand contained in the TBEV NS5 protein (Figure 2C) [22]. The region was cloned in pET28 plasmid, and the peptide expression was verified via Western blot. In a pull-down assay, this region bound to Scribble PDZ-4, but not to the control (Figure 2A). To further verify this interaction, we used a biotinylated peptide with sequence SRSATLVLAYLMLYHHL (157-173) to affinity purify the Scrib-4. The peptide sequence reproduced the alpha helix 6 (157-173) of the phosphatase and was bound to streptavidin beads through the biotin residue. Although the peptide was partially insoluble, the percentage of PDZ-4 domain retained on the peptide beads was significantly more than that retained on the control beads (Figure 2B).

Previous data showed that a tyrosine residue was relevant for the binding of NS5 protein to the PDZ-4 of Scribble [22]. The Dusp26 binding peptide contains two tyrosines (Y166 and Y170); therefore, we created three mutants substituting each or both with alanine. As shown in Figure 2D, E, the Y170A substitution had no effect on binding in the pull-down assay, while Y166A strongly diminished the binding. Interestingly, the multiple alignment showed that this region is conserved among similar phosphatases, and that Y166 is better conserved than Y170 (Figure 2C).

We performed a molecular docking analysis to generate structural models of the interaction. Crystal structures suggest that PDZ internal ligands usually bind in the same groove as the carboxyl-terminal peptides, which is formed by the $\beta 2$ strand, the $\alpha 2$ helix, and residues located along the $\beta 1-\beta 2$ loop, known as the carboxylate-binding loop [4]. For the docking analysis, we considered the PDZ-4 domain of the human Scribble protein (PDB 1UJU; residues 1-111 corresponding to 1096-1193 in Q14160) and the Dusp26 alpha-helix (PDB 4HRF, residues 156-172 in Q9BV47) and prepared the input structures for the docking with UCSF Chimera 1.14 software [29]. Docking poses were generated with HADDOCK software [25] to model the orientation of the peptide on the surface of the domain. The top-ranked cluster with the lowest HADDOCK score $(-84.1 \pm 1.2)$ is shown in Figure 3. In the model, the Dusp26 peptide formed an alpha-helix, and several residues, including Arg 158, Ser 159, Y166, Leu 167, and H171 were located at a distance lower than $3 \AA$ to amino acids of the PDZ-4 binding groove, potentially forming hydrogen bonds with the domain. Interestingly, residue E1109 (named E21 in the structure), which is specific for Scribble PDZ-4 according to the alignment (Figure 3D), may form a hydrogen bond with Dusp26 Y166. We cannot exclude, however, that the Dusp26 peptide makes additional contacts in a region of the PDZ domain different from the binding cleft. 

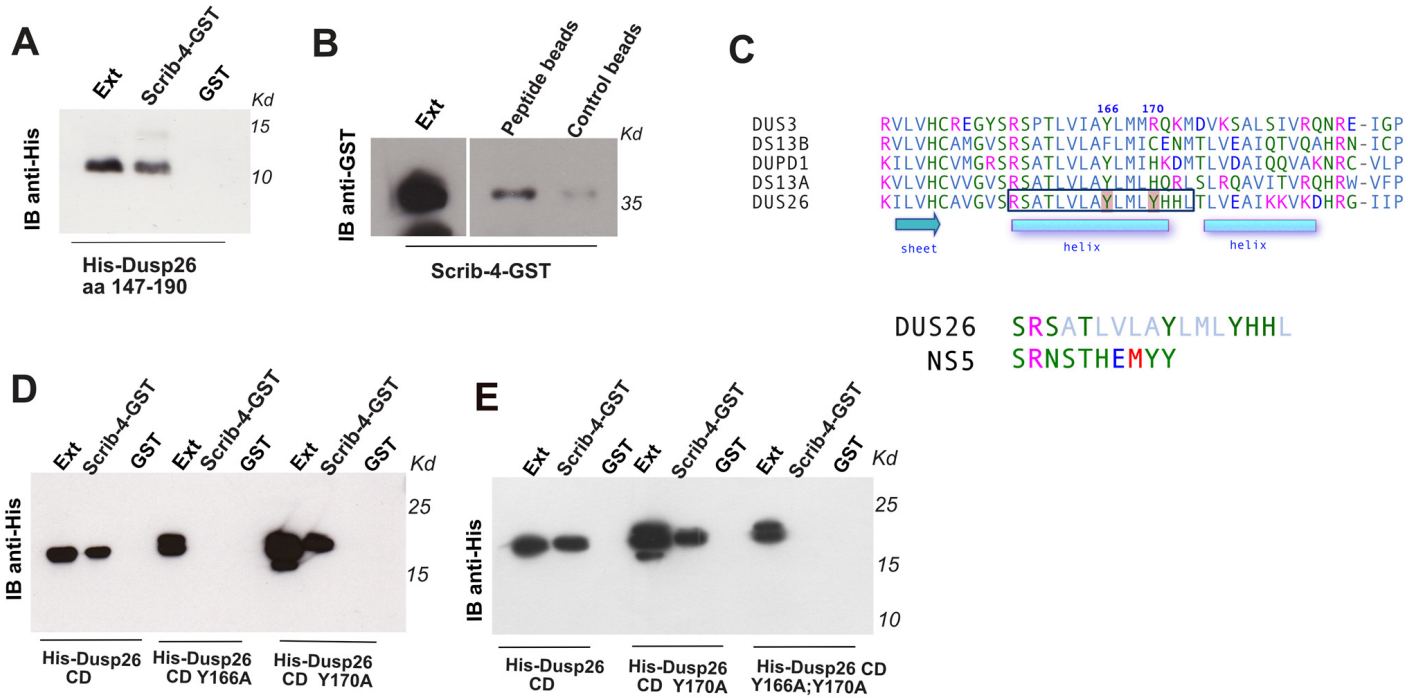

Figure 2. Dusp26 region (147-190) binds to Scribble PDZ-4. (A) Extracts containing His-Dusp26 (147-190) were incubated with Scrib-4-GST or GST alone (as a control) in a pull-down assay. Anti-His immunoblot revealed the bound phosphatase. (B) Biotinylated peptide SRSATLVLAYLMLYHHL (157-173) conjugated with streptavidin beads interacts with Scrib-4-GST. Extracts containing Scrib-4 were incubated with the conjugated peptide, and streptavidin beads alone were used as a control. Anti-GST immunoblot revealed the bound PDZ. (C) Multiple alignment of residues 147-190 of Dusp26 with the closest phosphatases according to Clustal Omega [31], showing the position of the binding peptide and of the two tyrosine residues. Dusp26 peptide was also compared to the NS5 peptide shown to bind to Scribble PDZ-4 in [22]. (D) Y166A mutation strongly reduced the binding of Dusp26 CD constructs to Scrib-4-GST, while Y170A had no effect in the pull-down assay. Anti-His immunoblot revealed the amount of phosphatase bound to the PDZ. (E) Double mutant Y166A/Y170A had a similar effect to Y166A in the pull-down assay.

A

B

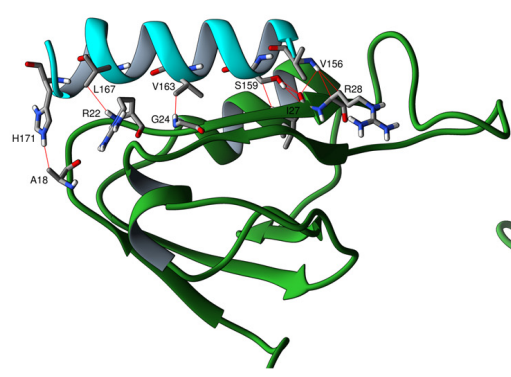

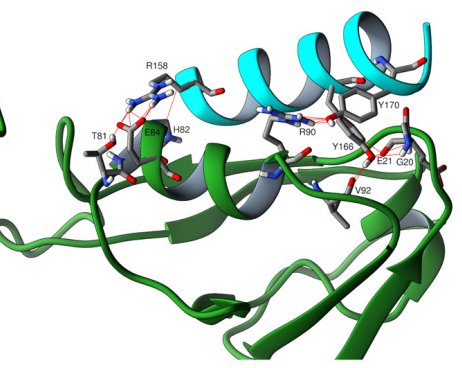

C

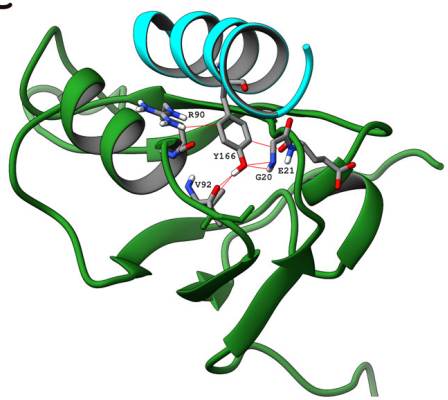

D

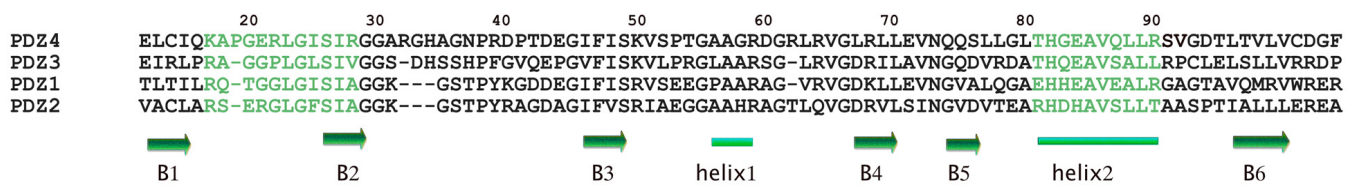

Figure 3. Ribbon diagrams of Dusp26-Scribble PDZ-4 structural models best ranked in HADDOCK analysis visualized with UCSF Chimera [29]. (A-C) Different orientations of the model are shown to highlight potential binding residues. Dusp26 peptide SRSATLVLAYLMLYHHL is colored in blue, while Scrib-4 is colored in green. Potential hydrogen bonds between atoms of the two proteins are indicated. (D) Multiple alignment of the four PDZ domains of Scribble according to Clustal Omega [31]. $\beta$ strands are indicated with a green arrow and $\alpha$ helices are with a green bar. Residues that form the binding pocket for the ligand are colored in green. For clarity, the residues numbers refer to the crystal structure PDB 1UJU. 


\section{Discussion}

Dusp26 is an atypical dual-specificity phosphatase with numerous MAPK and nonMAPK substrates [32]. Several lines of evidence suggest that Dusp26 targets are recruited through adaptor proteins that connect the phosphatase to the substrates [17,33-35]. An siRNA screening showed that knockdown of Dusp26 affects ERK regulation, and that the phosphatase has an inhibitory effect on ERK, but not on p38 [36]. Other studies suggest that ERK is targeted by the phosphatase; however, Dusp26 is unable to bind directly to ERK $[17,33]$. The role of the PDZ domains in the regulation of phosphorylation/dephosphorylation processes has been demonstrated in several studies; some phosphatases, including PTPN13, contain PDZ domains that interact simultaneously with different proteins to form functional complexes [37-39], while others have been shown to interact with PDZ containing proteins, to bring them in contact with their substrates or to localize them [40-42]. In particular, Scribble was suggested to bridge the phosphatase PHLPP1 to Akt [42], PP1g to ERK [43], and Dusp26 to Erk [17]. Scribble controls cell polarity and cell proliferation by integrating signals from various interactors, mainly through its four PDZ domains. It was shown to inhibit the activation of ERK1/2 and JNK1, possibly recruiting PP1g to the membrane [43,44]; more recently, it was suggested to promote YAP translocation into the nucleus by inhibiting its phosphorylation, through LATS1/2 kinase [45]. According to the Gtex portal (https://gtexportal.org/home/, accessed on 20 November 2021) and Human protein Atlas (https:/ / www.proteinatlas.org/ accessed on 20 November 2021), Scribble is co-expressed with Dusp26 in several tissues, including the skeletal muscle, artery, and many areas of the brain.

In the present study, we show that the fourth PDZ domain of Scribble is able to recognize an internal region of the Dusp26 encompassing amino acids 158-172. According to the docking model, we assume that this region makes contacts with amino acids of the PDZ binding pocket, but mutation analysis of the PDZ domain is needed to confirm this hypothesis. Our data show that a tyrosine residue of Dusp26 (Y166) plays a crucial role in its interaction with Scribble, and it is localized in the "AYLM" motif of Dusp26 which is well conserved in several other phosphatases, suggesting it may have a regulative role and leading to the hypothesis of a general mechanism of interaction of the phosphatases with scaffold PDZ domains. The involvement of PDZ modules may help the phosphatase to achieve specificity and to orchestrate its function in concert with the other cell signals. Interestingly, tyrosine 138 of Dusp3, which corresponds to Y166 of Dusp26, is phosphorylated to regulate the activity of the enzyme [46]. In high-throughput screening, the AYLM motif was also found to be phosphorylated in other phosphatases [47].

Atypical dual-specificity phosphatases are becoming more and more relevant as their complex network is further elucidated, and they seem to be promising drug targets to reprogram MAPK-dependent pathways altered in diseases [32,48]. However, the molecular mechanism that determines the target specificity of these enzymes is far from being elucidated, and too often the exact dephosphorylated residue is unknown, as is the phosphatase region that allows for the recognition. This knowledge is crucial for any clinical application, in order not to mislead the models, particularly for Dusp26 that has been recently associated with different pathologies such as cancer, as well as metabolic and neurodegenerative disorders $[49,50]$. Despite the fact that Dusp26, as many other phosphatases, has been considered an "undruggable" target, three chemical inhibitors of Dusp26 have been reported in literature. However, it is unlikely that they will be used clinically, mainly due to their off-target effects [32]. Our findings might be of particular interest in the development of novel and selective Dusp26 inhibitors for therapeutic applications.

Author Contributions: Conceptualization S.P. Methodology, Investigation and Validation S.P. and R.G.; R.G., E.D.S., F.S. and S.P. performed the experiments and analyzed the data. E.D.S. performed the Docking Analysis. Original Draft preparation S.P. Writing, review and editing S.P. and R.G. All authors have read and agreed to the published version of the manuscript.

Funding: This research was supported by "Fondi di Ateneo" 2020 from Università della Calabria to S.P. 
Institutional Review Board Statement: Not applicable.

Informed Consent Statement: Not applicable.

Data Availability Statement: Not applicable.

Acknowledgments: Molecular graphics and analyses were performed with UCSF Chimera, developed by the Resource for Biocomputing, Visualization, and Informatics at the University of California, San Francisco, with support from NIH P41-GM103311. HADDOCK software was developed by Alexandre Bonvin and members of the computational structural biology group, Utrecht University.

Conflicts of Interest: The authors declare no conflict of interest.

\section{References}

1. Pawson, T.; Raina, M.; Nash, P. Interaction domains: From simple binding events to complex cellular behavior. FEBS Lett. 2001, 513, 2-10. [CrossRef]

2. Zucconi, A.; Panni, S.; Paoluzi, S.; Castagnoli, L.; Dente, L.; Cesareni, G. Domain repertoires as a tool to derive protein recognition rules. FEBS Lett. 2000, 480, 49-54. [CrossRef]

3. Harris, B.Z.; Lim, W.A. Mechanism and role of PDZ domains in signaling complex assembly. J. Cell Sci. 2001, 114, 3219-3231. [CrossRef] [PubMed]

4. Liu, X.; Fuentes, E.J. Emerging themes in PDZ domain signaling: Structure, function, and inhibition. Int. Rev. Cell Mol. Biol. 2019, 343, 129-218.

5. Christensen, N.R.; Čalyševa, J.; Fernandes, E.F.A.; Lüchow, S.; Clemmensen, L.S.; Haugaard-Kedström, L.M.; Strømgaard, K. PDZ Domains as Drug Targets. Adv. Ther. 2019, 2, 1800143. [CrossRef] [PubMed]

6. Doyle, D.A.; Lee, A.; Lewis, J.; Kim, E.; Sheng, M.; MacKinnon, R. Crystal Structures of a Complexed and Peptide-Free Membrane Protein-Binding Domain: Molecular Basis of Peptide Recognition by PDZ. Cell 1996, 85, 1067-1076. [CrossRef]

7. Luck, K.; Charbonnier, S.; Travé, G. The emerging contribution of sequence context to the specificity of protein interactions mediated by PDZ domains. FEBS Lett. 2012, 586, 2648-2661. [CrossRef]

8. Ivarsson, Y.; Arnold, R.; McLaughlin, M.; Nim, S.; Joshi, R.; Ray, D.; Liu, B.; Teyra, J.; Pawson, T.; Moffat, J.; et al. Large-scale interaction profiling of PDZ domains through proteomic peptide-phage display using human and viral phage peptidomes. Proc. Natl. Acad. Sci. USA 2014, 111, 2542-2547. [CrossRef]

9. Songyang, Z.; Fanning, A.S.; Fu, C.; Xu, J.; Marfatia, S.M.; Chishti, A.H.; Crompton, A.; Chan, A.C.; Anderson, J.M.; Cantley, L.C. Recognition of Unique Carboxyl-Terminal Motifs by Distinct PDZ Domains. Science 1997, 275, 73-77. [CrossRef]

10. Stricker, N.L.; Christopherson, K.S.; Yi, B.A.; Schatz, P.J.; Raab, R.W.; Dawes, G.; Bassett, D.E.; Bredt, D.S.; Li, M. PDZ domain of neuronal nitric oxide synthase recognizes novel C-terminal peptide sequences. Nat. Biotechnol. 1997, 15, 336-342. [CrossRef]

11. Tonikian, R.; Zhang, Y.; Sazinsky, S.L.; Currell, B.; Yeh, J.-H.; Reva, B.; Held, H.A.; Appleton, B.A.; Evangelista, M.; Wu, Y.; et al. A Specificity Map for the PDZ Domain Family. PLOS Biol. 2008, 6, e239. [CrossRef]

12. Hillier, B.J.; Christopherson, K.S.; Prehoda, K.E.; Bredt, D.S.; Lim, W.A. Unexpected modes of PDZ domain scaffolding revealed by structure of nNOS-syntrophin complex. Science 1999, 284, 812-815. [CrossRef] [PubMed]

13. Lenfant, N.; Polanowska, J.; Bamps, S.; Omi, S.; Borg, J.-P.; Reboul, J. A genome-wide study of PDZ-domain interactions in C. elegans reveals a high frequency of non-canonical binding. BMC Genom. 2010, 11, 671. [CrossRef]

14. Ali, M.; McAuley, M.M.; Lüchow, S.; Knapp, S.; Joerger, A.C.; Ivarsson, Y. Integrated analysis of Shank1 PDZ interactions with C-terminal and internal binding motifs. Curr. Res. Struct. Biol. 2021, 3, 41-50. [CrossRef]

15. Zhang, Y.; Appleton, B.A.; Wiesmann, C.; Lau, T.; Costa, M.; Hannoush, R.N.; Sidhu, S.S. Inhibition of Wnt signaling by Dishevelled PDZ peptides. Nat. Chem. Biol. 2009, 5, 217-219. [CrossRef] [PubMed]

16. Penkert, R.R.; DiVittorio, H.M.; Prehoda, K.E. Internal recognition through PDZ domain plasticity in the Par-6-Pals1 complex. Nat. Struct. Mol. Biol. 2004, 11, 1122-1127. [CrossRef] [PubMed]

17. Sacco, F.; Boldt, K.; Calderone, A.; Panni, S.; Paoluzi, S.; Castagnoli, L.; Ueffing, M.; Cesareni, G. Combining affinity proteomics and network context to identify new phosphatase substrates and adapters in growth pathways. Front. Genet. 2014, 5, 115. [CrossRef]

18. Luck, K.; Fournane, S.; Kieffer, B.; Masson, M.; Nominé, Y.; Travé, G. Putting into Practice Domain-Linear Motif Interaction Predictions for Exploration of Protein Networks. PLoS ONE 2011, 6, e25376. [CrossRef]

19. Lim, K.; Godde, N.; Humbert, P.O.; Kvansakul, M. Structural basis for the differential interaction of Scribble PDZ domains with the guanine nucleotide exchange factor $\beta$-PIX. J. Biol. Chem. 2017, 292, 20425-20436. [CrossRef] [PubMed]

20. Takizawa, S.; Nagasaka, K.; Nakagawa, S.; Yano, T.; Nakagawa, K.; Yasugi, T.; Takeuchi, T.; Kanda, T.; Huibregtse, J.M.; Akiyama, T.; et al. Human scribble, a novel tumor suppressor identified as a target of high-risk HPV E6 for ubiquitin-mediated degradation, interacts with adenomatous polyposis coli. Genes Cells 2006, 11, 453-464. [CrossRef]

21. Janezic, E.M.; Harris, D.-A.; Dinh, D.; Lee, K.-S.; Stewart, A.; Hinds, T.R.; Hsu, P.L.; Zheng, N.; Hague, C. Scribble co-operatively binds multiple $\alpha 1 D$-adrenergic receptor C-terminal PDZ ligands. Sci. Rep. 2019, 9, 14073. [CrossRef]

22. Werme, K.; Wigerius, M.; Johansson, M. Tick-borne encephalitis virus NS5 associates with membrane protein scribble and impairs interferon-stimulated JAK-STAT signalling. Cell. Microbiol. 2008, 10, 696-712. [CrossRef] 
23. Richier, L.; Williton, K.; Clattenburg, L.; Colwill, K.; O’Brien, M.; Tsang, C.; Kolar, A.; Zinck, N.; Metalnikov, P.; Trimble, W.S.; et al. NOS1AP Associates with Scribble and Regulates Dendritic Spine Development. J. Neurosci. 2010, 30, 4796-4805. [CrossRef] [PubMed]

24. Melik, W.; Ellencrona, K.; Wigerius, M.; Hedström, C.; Elväng, A.; Johansson, M. Two PDZ binding motifs within NS5 have roles in Tick-borne encephalitis virus replication. Virus Res. 2012, 169, 54-62. [CrossRef] [PubMed]

25. van Zundert, G.; Rodrigues, J.; Trellet, M.; Schmitz, C.; Kastritis, P.; Karaca, E.; Melquiond, A.; van Dijk, M.; de Vries, S.; Bonvin, A. The HADDOCK2.2 Web Server: User-Friendly Integrative Modeling of Biomolecular Complexes. J. Mol. Biol. 2015, 428, 720-725. [CrossRef]

26. De Vries, S.J.; Bonvin, A.M.J.J. CPORT: A Consensus Interface Predictor and Its Performance in Prediction-Driven Docking with HADDOCK. PLoS ONE 2011, 6, e17695. [CrossRef]

27. Méndez, R.; Leplae, R.; De Maria, L.; Wodak, S. Assessment of blind predictions of protein-protein interactions: Current status of docking methods. Proteins: Struct. Funct. Bioinform. 2003, 52, 51-67. [CrossRef]

28. Xue, L.C.; Rodrigues, J.P.; Kastritis, P.L.; Bonvin, A.M.; Vangone, A. PRODIGY: A web server for predicting the binding affinity of protein-protein complexes. Bioinformatics 2016, 32, 3676-3678. [CrossRef]

29. Pettersen, E.F.; Goddard, T.D.; Huang, C.C.; Couch, G.S.; Greenblatt, D.M.; Meng, E.C.; Ferrin, T.E. UCSF Chimera-A visualization system for exploratory research and analysis. J. Comput. Chem. 2004, 25, 1605-1612. [CrossRef]

30. Lokareddy, R.K.; Bhardwaj, A.; Cingolani, G. Atomic Structure of Dual-Specificity Phosphatase 26, a Novel p53 Phosphatase. Biochemistry 2013, 52, 938-948. [CrossRef]

31. Sievers, F.; Wilm, A.; Dineen, D.; Gibson, T.J.; Karplus, K.; Li, W.; Lopez, R.; McWilliam, H.; Remmert, M.; Söding, J.; et al. Fast, scalable generation of high-quality protein multiple sequence alignments using Clustal Omega. Mol. Syst. Biol. $2011,7,539$. [CrossRef] [PubMed]

32. Thompson, E.; Stoker, A. A Review of DUSP26: Structure, Regulation and Relevance in Human Disease. Int. J. Mol. Sci. 2021, 22, 776. [CrossRef] [PubMed]

33. Hu, Y.; Mivechi, N.F. Association and Regulation of Heat Shock Transcription Factor $4 \mathrm{~b}$ with both Extracellular Signal-Regulated Kinase Mitogen-Activated Protein Kinase and Dual-Specificity Tyrosine Phosphatase DUSP26. Mol. Cell. Biol. 2006, 26, 3282-3294. [CrossRef] [PubMed]

34. Tanuma, N.; Nomura, M.; Ikeda, M.; Kasugai, I.; Tsubaki, Y.; Takagaki, K.; Kawamura, T.; Yamashita, Y.; Sato, I.; Sato, M.; et al. Protein phosphatase Dusp26 associates with KIF3 motor and promotes N-cadherin-mediated cell-cell adhesion. Oncogene 2008, 28, 752-761. [CrossRef]

35. Kim, H.; Lee, H.-J.; Oh, Y.; Choi, S.-G.; Hong, S.-H.; Kim, H.-J.; Lee, S.-Y.; Choi, J.-W.; Hwang, D.S.; Kim, K.-S.; et al. The DUSP26 phosphatase activator adenylate kinase 2 regulates FADD phosphorylation and cell growth. Nat. Commun. 2014, 5, 3351. [CrossRef]

36. Sacco, F.; Gherardini, P.; Paoluzi, S.; Saez-Rodriguez, J.; Helmer-Citterich, M.; Ragnini, A.; Castagnoli, L.; Cesareni, G. Mapping the human phosphatome on growth pathways. Mol. Syst. Biol. 2012, 8, 603. [CrossRef]

37. Cuppen, E.; Gerrits, H.; Pepers, B.; Wieringa, B.; Hendriks, W. PDZ Motifs in PTP-BL and RIL Bind to Internal Protein Segments in the LIM Domain Protein RIL. Mol. Biol. Cell 1998, 9, 671-683. [CrossRef]

38. Kock, G.; Dicks, M.; Yip, K.T.; Kohl, B.; Pütz, S.; Heumann, R.; Erdmann, K.S.; Stoll, R. Molecular Basis of Class III Ligand Recognition by PDZ3 in Murine Protein Tyrosine Phosphatase PTPN13. J. Mol. Biol. 2018, 430, 4275-4292. [CrossRef]

39. Chen, K.-E.; Lin, S.-Y.; Wu, M.-J.; Ho, M.-R.; Santhanam, A.; Chou, C.-C.; Meng, T.-C.; Wang, A.H.-J. Reciprocal allosteric regulation of p38 $\gamma$ and PTPN3 involves a PDZ domain-modulated complex formation. Sci. Signal. 2014, 7, ra98. [CrossRef]

40. Iuliano, R.; Trapasso, F.; Samà, I.; Le Pera, I.; Martelli, M.L.; Lembo, F.; Santoro, M.; Viglietto, G.; Chiariotti, L.; Fusco, A. Rat protein tyrosine phosphatase $\eta$ physically interacts with the PDZ domains of syntenin. FEBS Lett. 2001, 500, 41-44. [CrossRef]

41. Takahashi, Y.; Morales, F.C.; Kreimann, E.L.; Georgescu, M.-M. PTEN tumor suppressor associates with NHERF proteins to attenuate PDGF receptor signaling. EMBO J. 2006, 25, 910-920. [CrossRef] [PubMed]

42. Li, X.; Yang, H.; Liu, J.; Schmidt, M.D.; Gao, T. Scribble-mediated membrane targeting of PHLPP1 is required for its negative regulation of Akt. EMBO Rep. 2011, 12, 818-824. [CrossRef] [PubMed]

43. Nagasaka, K.; Seiki, T.; Yamashita, A.; Massimi, P.; Subbaiah, V.K.; Thomas, M.; Kranjec, C.; Kawana, K.; Nakagawa, S.; Yano, T.; et al. A Novel Interaction between hScrib and PP1 $\gamma$ Downregulates ERK Signaling and Suppresses Oncogene-Induced Cell Transformation. PLoS ONE 2013, 8, e53752. [CrossRef] [PubMed]

44. Dow, L.E.; Elsum, I.A.; King, C.L.; Kinross, K.M.; Richardson, H.E.; Humbert, P.O. Loss of human Scribble cooperates with H-Ras to promote cell invasion through deregulation of MAPK signalling. Oncogene 2008, 27, 5988-6001. [CrossRef]

45. Shen, H.; Huang, C.; Wu, J.; Li, J.; Hu, T.; Wang, Z.; Zhang, H.; Shao, Y.; Fu, Z. SCRIB Promotes Proliferation and Metastasis by Targeting Hippo/YAP Signalling in Colorectal Cancer. Front. Cell Dev. Biol. 2021, 9, 656359. [CrossRef] [PubMed]

46. Alonso, A.; Rahmouni, S.; Williams, S.; Van Stipdonk, M.; Jaroszewski, L.; Godzik, A.; Abraham, R.T.; Schoenberger, S.P.; Mustelin, T. Tyrosine phosphorylation of VHR phosphatase by ZAP-70. Nat. Immunol. 2003, 4, 44-48. [CrossRef]

47. Hornbeck, P.V.; Zhang, B.; Murray, B.; Kornhauser, J.M.; Latham, V.; Skrzypek, E. PhosphoSitePlus, 2014: Mutations, PTMs and recalibrations. Nucleic Acids Res. 2014, 43, D512-D520. [CrossRef]

48. Jeffrey, K.L.; Camps, M.; Rommel, C.; Mackay, C.R. Targeting dual-specificity phosphatases: Manipulating MAP kinase signalling and immune responses. Nat. Rev. Drug Discov. 2007, 6, 391-403. [CrossRef] 
49. Chen, J.; Zeng, Y.; Wu, R.; Xuan, Y.; Jiang, M.; Teng, H. Corrigendum: Decreased DUSP26 Expression Promotes Malignant Behavior in Glioblastoma Cells via Deregulation of MAPK and Akt Signaling Pathway. Front. Oncol. 2021, 11, 676647. [CrossRef]

50. Wang, Y.; Han, D.; Zhou, T.; Chen, C.; Cao, H.; Zhang, J.Z.; Ma, N.; Liu, C.; Song, M.; Shi, J.; et al. DUSP26 induces aortic valve calcification by antagonizing MDM2-mediated ubiquitination of DPP4 in human valvular interstitial cells. Eur. Hear. J. 2021, 42, 2935-2951. [CrossRef] 